\title{
The Digital Circular Economy: Can the Digital Transformation Pave the Way for Resource-Efficient Materials Cycles?
}

\author{
Henning Wilts* and Holger Berg \\ Wuppertal Institute für Klima, Umwelt, Döppersberg, Germany
}

Submission: December 13, 2017; Published: December 21, 2017

*Corresponding author: Henning Wilts, Wuppertal Institut für Klima, Umwelt, Energie GmbH (WI) Döppersberg 19, 42103 Wuppertal, Germany, Tel:02022492-139; Email:henning.wilts@wupperinst.org

\begin{abstract}
Despite the recent interest in a circular economy, recycled materials are being fed back into production processes at volumes that are far below what is possible. If this system were to be improved, loss of value, dependence on volatile commodity markets, lower resource productivity, and externalities in the form of environmental pollution could be avoided. A drive towards digitalisation in industry and the waste management sector could make this happen.

Keywords: Digitalisation; Circular Economy; Transformation; Resource-Efficiency; Fourth Industrial Revolution

Abbreviations: BMUB: German Federal Ministry for the Environment, Nature Conservation, Building and Nuclear Safety; EEA: European Environment Agency; SMEs: Small and Medium-sized Enterprises
\end{abstract}

\section{Introduction}

Germany's waste management system is one of the world's most advanced - its primary objective is to dispose of waste in a way that is safe for both people and the environment. However, only about 14 per cent of the raw materials used in industry are derived from recycling processes; the remainder are still sourced from primary materials ${ }^{1}$. The circular economy is not yet being implemented on a large enough scale. Recyclates or recycled materials, i.e. secondary raw materials recovered from waste, are being fed back into production and usage processes at volumes that are far below what is possible. If this system were to be improved, loss of value, dependence on volatile commodity markets, lower resource productivity, and externalities in the form of environmental pollution could be avoided [1]. A drive towards digitalisation in industry and the waste management sector could make this happen. A study by the German Federal Ministry for the Environment, Nature Conservation, Building and Nuclear Safety (BMUB) indicates that no other lead market in the environmental sector stands to benefit from digitalisation more than the circular economy - and that, at the same time, no sector has ever been so poorly positioned ${ }^{2}$.

\section{The circular economy as a way to achieve greater conservation of resources}

The transformation of global production and consumption patterns into a circular economy model is high on the political agenda. For example, the European Commission has produced an action plan for the circular economy and the UN's Sustainable
Development Goals (SDGs) also prominently set out closed-loop principles under SDG 12, "Ensure sustainable consumption and production patterns ${ }^{4}$.

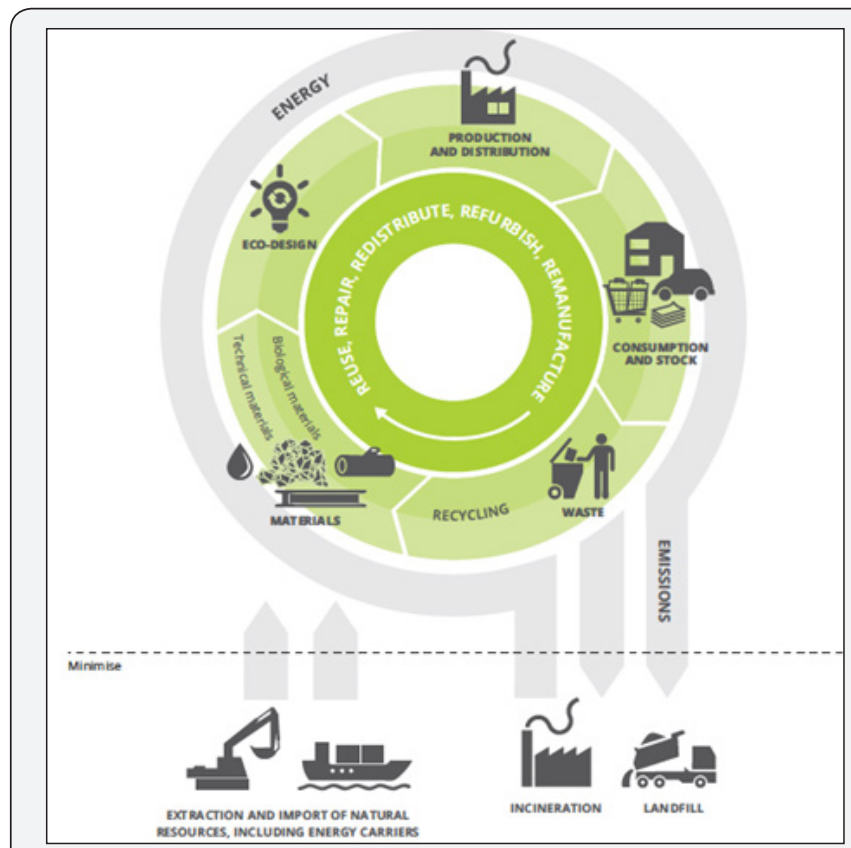

Figure 1: The circular economy concept.

The fundamental idea behind the circular, or closed-loop, economy is to retain as much value as possible from products and components when they reach the end of their useful life. 
This requires an integrated approach that, for example, takes the recyclability of products into account during the design phase, extends their usage process and ensures materials can be substantially recovered after use. This is illustrated in Figure 1, which shows how products can be managed in the production and use cycle through various means including reuse and recycling. There are high hopes associated with this system [2-4]:

a) It is expected that the circular economy will lead to a much more efficient use of natural resources, and that the reduction in demand for materials will also make a substantial contribution towards a low carbon economy.

b) It should also ensure the competitiveness of the specific market, for example by reducing supply risks for industry or developing innovative business models, such as sharing or leasing.

In addition, it is intended that the circular economy will also create jobs and new employment opportunities.

I. The European Commission hopes to provide 580,000 new jobs, reduce greenhouse gas emissions by 450 million tonnes until 2030, and cut costs of 600 million euros for European companies, which would be around $8 \%$ of its annual turnover and create new and lasting competitive advantages for Europe ${ }^{5}$. A progress report on the implementation of the circular economy package, published for the first time in 2017, does not hide the challenges of such a transformation; so far, one could not agree on any indicators that measure the ability of the European economy to operate on a circular basis. However, it underlines the ecological and economic potential that could be achieved through comprehensive ecodesign, green public procurement or improved financing conditions for the circular economy ${ }^{5}$.

\section{The circular economy's implementation is primarily a problem of information}

In the light of all this potential, we are faced with the question of why we are still so far from operating closed-loop systems in reality. Central to the effective design of the circular economy is the observation that this has hitherto failed primarily as a result of problems of information. As far back as 1970, Nobel Prizewinning economist George A kerlof commented that fewer used cars are traded than is actually possible. This is due to the fact that potential buyers do not know whether a vehicle will keep working for a few more years, or if it is only fit for scrap. In American slang, cars that are defective but nevertheless sold on are known as "lemons", hence the term "the market for lemons" [5-9]. However, if customers were informed about the quality of the car with reasonable assurance, the incentive to buy would be greater and the use of existing products would likewise be more intensive. Further studies have expanded on this idea and developed a firm diagnosis, according to which the information deficit can be divided into four areas ${ }^{7}$ :

\section{Underdeveloped availability of information:}

A. The quality of recyclates is often uncertain. There is a lack of data relating, for example, to purity, the type and amount of additives, etc., which is critical when it comes to reuse.

B. Information about available quantities of recycled resources on the market is not transparent; economies of scale are therefore not achieved and recyclates become unnecessarily expensive.

C. "Lemon markets" develop, so that high-quality recyclates do not reach the market directly or are not put to the best possible use.

\section{Increased transaction and search costs:}

A. Unclear information about the quality of secondary materials increases the burden on users to find and use this data.

B. This lack of information complicates pricing processes and increases the outlay on drawing up contracts and guarantees.

C. The absence of a functioning value creation network between industry and the waste management sector also results in high search costs.

\section{Potential customers have a distorted perception:}

A. Secondary materials are generally considered inferior.

B. There is a lack of knowledge about the general usability of secondary materials.

C. Another consequence of the lack of information is that externalities (such as air and environmental pollution) in the primary markets are not costed in, resulting in unjustified price advantages for primary materials.

\footnotetext{
${ }^{1}$ Institut der deutschen Wirtschaft (2010) Studie im Auftrag des BDE, Köln

${ }^{2}$ BMUB (2016) Digitalisierung der GreenTech-Branche lohnt sich. Pressemitteilung Nr. 297/16 Berlin.

${ }^{3}$ European Commission (2015) Closing the loop - An EU action plan for the Circular Economy. COM(2015) 614 final, Brüssel.

${ }^{4}$ UN SDG 12: Ensure sustainable consumption and production patterns.

${ }^{5}$ European Commission (2015) An Ambitious EU Circular Economy Package. Factsheets on the circular economy, Brussels.

${ }^{6}$ European Commission (2017) Report on the implementation of the Circular Economy Action Plan. COM(2017) 33 final Brussels.

${ }^{7}$ OECD (2005) Improving Recycling Markets. Working Group on Waste Prevention and Recycling Paris.
} 
Technological barriers: Recyclability is not perceived as a competitive advantage.

Poor design increases recycling costs: These problems mean that it often still makes sense to companies to invest in primary materials instead of recycled raw materials - although the latter may actually be cheaper. This is set against a background of inadequate information, because when and where waste is produced that could be used as a secondary raw material is much less clear than is the case for primary materials obtained through activities such as mining. Furthermore, the value of waste materials is highly dependent on what is known about their composition: which are the waste materials that are hazardous and expensive to dispose of, and what waste is practical to recycle? These problems could be alleviated by an improved availability of information.

\section{Digital transformation as the ideal enabler for the circular economy}

The transition to a circular economy will make enhanced coordination of material flows and information flows absolutely essential if the issues described are to be tackled. Information about the quantity and especially the quality of products and the raw materials they contain must be gathered and retained. This data must also be kept together with the materials in the cycle, so that waste can become a processable resource. A key challenge in this process lies in effectively generating, collecting, processing and making available the volume of information about the material composition of each individual product, its use patterns, its location within the waste system, etc. All of this is necessary to establish functioning markets and cycles in the next stage. This will make efficient, market-based solutions possible, rather than just regulation.

Until now, it has not been possible to overcome much of this information deficit. However, the application of elements of the digital transformation could now deliver precisely this solution after all, in many ways it is primarily an information revolution. It may therefore be considered as the "missing link" to the implementation of the circular economy. The following are some examples of ways in which this could be achieved:

A. Cyber-physical systems allow products to carry information at least through the entire production process. For the purposes of the circular economy, this information must extend across the entire life cycle and also include environment-related information, such as material composition or even "footprints". This way, instances of information asymmetry can be meaningfully reduced.

B. Sensoring enables the real-time collection and generation of data in Industry 4.0. Up-to-date, detailed information about the precise location of waste production, its exact material composition, etc. can be recorded ("fast data") and passed on to other companies, which then use it to plan their production processes. Data analytics applications ("big data") can then deliver and project information about subsequent use, practical logistics solutions, etc.

C. Matching supply and demand in line with waste or secondary raw materials can be revolutionised by the use of Internet-based solutions, as is already the case today for the distribution of products. A prospective automated market and logistics platform (a sort of "Uber for waste") has the potential to reduce search and transaction costs. It could also make it easier to achieve economies of scale, since there would be more clarity about material quantities.

D. In an intelligent overall system of this kind, it would even be conceivable that products that are available for recycling could automatically create their own markets via the Internet of Things by marketing themselves on such platforms on the basis of information about composition and possible uses. Some recyclates are already less expensive than primary materials, and this idea of "self-marketing" could increase this trend. Recyclability would then also become a technical competitive advantage.

E. Block chain applications - already used as the basis of the virtual currency Bitcoin, for example - could be used to share information in an anonymous and encrypted form, without competitors being able to trace the data back to proprietary production technologies. The solutions outlined here - and other approaches besides - have not, however, thus far been used to a sufficient degree to establish a circular economy. The following section explains how this could be facilitated.

\section{Conclusion}

Promising solutions to the problem of establishing a circular economy will need to go much further than simple waste disposal solutions, come into effect much earlier in the production process and, for example, include consumption-related decisions to a greater extent than before. The aim must be to prevent waste as far as possible and to enable a resource-efficient circular economy. To that end, the Wuppertal Institute is working to develop circular economy literacy: how can such comprehensive change processes be made possible, evaluated and set on the right tracks? One key priority lies in supporting the public authorities in establishing a political framework for these developments. This approach must bring together the various stakeholders and provide a strategic vision for a digital circular economy in North Rhine-Westphalia, Germany and Europe: everyone wants digitalisation, everyone wants a circular economy - but what is the shared vision, and how do we achieve it? The following four points will be of particular importance.

A. Building bridges: linking digitalisation and the circular economy: North Rhine-Westphalia, alongside other German federal states, has long recognised the importance of the issues of digitalisation and the circular economy, and has launched various initiatives. But the platforms on which to systematically link these two issues have not been in place. A competence centre for the digital circular economy would offer the opportunity to bring together approaches from 
the world of digitalisation and challenges from the circular economy, and to develop consultancy services for innovative business models.

B. Closing gaps: dedicated support for SMEs: If the structure of companies within the circular economy is compared with that of the classic "linear economy", it is evident that there is a significantly higher proportion of small- and medium-sized enterprises (SMEs) for which the process of digitalisation will present a particular challenge. Especially SMEs will need special support if they are to be able to deal intensively with the subject addressed here. Challenges include the need for high levels of investment and thus high risks despite significant prospects of success, a plethora of as yet unsettled legal questions (such as the protection of data and intellectual property) and, frequently, a simple lack of capacity.

C. Providing guidance: where is the digital circular economy making progress?: In order to establish the right framework for such a process of transformation, information is urgently required about where relevant potential for a digital transformation to close material cycles and corresponding business models on circular economy principles can be found. Indicators of "digital readiness" based on studies of technology trends and status quo analyses - for example for individual materials or for target groups such as SMEs - could provide important points of reference for policymakers and businesses.

D. The big picture: in what areas can the digital circular economy make a real difference?: At the same time, we should only aim to close those cycles where to do so will contribute to the conservation of resources. When it comes to existing, "linearly" designed products, materials-based recycling, for example, is not always ecologically worthwhile. The use of additional information and communications technologies in such cases could merely lead to further losses of critical raw materials such as tantalum and indium, for which adequate recycling technologies have not yet been made available. This will also require comprehensive analyses for evaluating digitalisation processes.
If the circular economy is to become established, industry, the waste management sector and companies developing software and technologies for the digital transformation will need to be networked so that a functioning value creation network can be built. Recycling solutions can therefore be taken into account at the same time as this network is implemented for the most costeffective results. The window of opportunity for this is now! The transition to Industry 4.0, the Internet of Things and similar developments are already underway. Every delayed or later introduction would, however, require significant additional costs as well as expensive system adjustments. Furthermore, although Germany is still a world leader when it comes to exporting technologies for the circular economy, this advantage will be seriously threatened if Germany does not start to make major investments in the digitalisation of its own circular economy soon. References

1. Wilts, Henning (2017) Waste Prevention: A survey of policies and programmes across the OECD. OECD (Editor) Paris, France.

2. Wilts, Henning (2017) Die Ressourcen zirkulieren lassen. [Facilitating the circulation of resources] Factory p. 9-14.

3. EEA (Editor) (2017) Circular by design. Products in the circular economy. Copenhagen.

4. Wilts, Henning, van Barneveld, Joost, van der Veen, Geert, et al. (2017) Regulatorische Hemmnisse für die Kreislaufwirtschaft. [Regulatory barriers to the circular economy] pp. 156-162.

5. Wilts, Henning (2016) Germany on the road to a circular economy? WISO Diskurs Bonn.

6. Wilts, Henning, von Gries, Nadja, Bahn-Walkowiak, Bettina (2016) From Waste Management to Resource Efficiency-The Need for Policy Mixes. Sustainability 8(7).

7. Berg, Holger, Bienge, Katrin (2015) Ressourcenbezogene Key Performance Indikatoren. [Resource-related key performance indicators]. Ressourcen Politik.

8. Berg, Holger (2014) RessourcenKooperation - Ressourceneffizienz in der Wertschöpfungskette durch Unternehmenskooperation. [ResourceCooperation - Resource Efficiency in the Value Chain by Business Cooperation]. Wuppertal Institut für Klima, Umwelt und Energie (Eds.) Wuppertal.

9. Susanne Fischer, Henning Wilts (2017) Economics of Waste Prevention. Recreate Report 4(4).

\begin{tabular}{|l|}
\hline \multicolumn{1}{|c|}{ Your next submission with Juniper Publishers } \\
will reach you the below assets \\
- Quality Editorial service \\
- Swift Peer Review \\
- Reprints availability \\
- E-prints Service \\
- Manuscript Podcast for convenient understanding \\
- Global attainment for your research \\
- Manuscript accessibility in different formats \\
( Pdf, E-pub, Full Text, Audio) \\
- Unceasing customer service \\
Track the below URL for one-step submission \\
https://juniperpublishers.com/online-submission.php \\
\hline
\end{tabular}

